\title{
Communication of advance care planning decisions: a retrospective cohort study of documents in general practice
}

\author{
Laura Panozzo $^{1^{*}}$ (D), Pam Harvey ${ }^{1,2}$, Meagan-Jane Adams ${ }^{3}$, Dennis $\mathrm{O}^{\prime}$ Connor $^{1}$ and Bernadette Ward ${ }^{1 *}$
}

\begin{abstract}
Background: Doctors, particularly general practitioners, play a significant role in assisting patients to create advance care plans. When medically indicated, these documents are important tools to promote congruence between endof-life care and patient's personal preferences. Despite this, little is known regarding the availability of these documents in hospitals. The aim of this study was to identify the proportion of people who died in hospital without an advance care plan and how many of these had advance care planning (ACP) documents in their general practice records.
\end{abstract}

Methods: A retrospective cohort study was conducted of patient hospital records with manual linkage to general practice records. The large regional hospital in Victoria, Australia has a catchment population in excess of 300,000 people. The study sample was patients aged 75 years and over who died in the hospital between 1 January 2016 and 31 December 2017. The hospital records of these patients were examined to identify those which did not have a system alert for ACP documents on the file. Alerted ACP documents were limited to those legislated in the state of Victoria: advance care plan, Enduring Power of Attorney (Medical Treatment) or Enduring Power of Guardianship. Where no ACP document system alert was found in the hospital record, the patient's nominated general practice was consented to participate and the corresponding general practice record was examined. Data were analysed using descriptive statistics.

Results: Of the 406 patients who died in hospital, 76.1\% (309) did not have a system alert for any ACP document. Of the 309 hospital records without a system alert, 144 (46.7\%) corresponding general practice records were examined. Of these, $14.6 \%$ included at least one ACP document, including four advance care plans, that were not available in hospital.

Conclusions: Unless ACP documents are consistently communicated from general practice, patient's preferences may be unknown during end-of-life care. It is important that both doctors and patients are supported to use connected electronic health records to ensure that documents are readily available to healthcare staff when they are required.

Keywords: Advance care planning, End-of-life care., Palliative medicine., General practice.

\footnotetext{
* Correspondence: lepan1@student.monash.edu;

bernadette.ward@monash.edu

'School of Rural Health, Monash University, 26 Mercy Street, Bendigo, Victoria

3550, Australia

Full list of author information is available at the end of the article
}

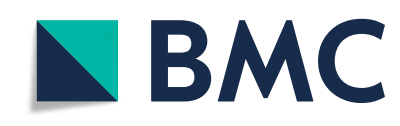

(c) The Author(s). 2020 Open Access This article is licensed under a Creative Commons Attribution 4.0 International License, which permits use, sharing, adaptation, distribution and reproduction in any medium or format, as long as you give appropriate credit to the original author(s) and the source, provide a link to the Creative Commons licence, and indicate if changes were made. The images or other third party material in this article are included in the article's Creative Commons licence, unless indicated otherwise in a credit line to the material. If material is not included in the article's Creative Commons licence and your intended use is not permitted by statutory regulation or exceeds the permitted use, you will need to obtain permission directly from the copyright holder. To view a copy of this licence, visit http://creativecommons.org/licenses/by/4.0/. The Creative Commons Public Domain Dedication waiver (http://creativecommons.org/publicdomain/zero/1.0/) applies to the data made available in this article, unless otherwise stated in a credit line to the data. 


\section{Background}

Education campaigns have aimed to increase both the awareness of advance care planning (ACP) discussions, and prevalence of ACP documents $[1,2]$. Health practitioners have become more familiar and confident in their ability, to use these documents, to make decisions during end-of-life care that support patients' preferences [3]. These documents play a particularly important role when a patient has lost decision making capacity and can no longer communicate for themselves [4, 5]. Ensuring a patient's preferences are fulfilled is the most common priority for health practitioners during end-of-life care [3]. Engagement with, and completion of, ACP documents is influenced by cultural factors [6]. In Australia, ACP conversations can be emotionally challenging for both patients and practitioners but are of great value [7].

In Australia, ACP documents primarily include an advance care plan as a written statement of preferences or a document formally appointing a substitute decision maker; however, the specific terminology varies across jurisdictions [4, 8]. The state government of Victoria provides an ACP document template, however advance care plans can be constructed on any written form if it fulfils the relevant legal requirements $[3,5$, 8]. Historically, legal representatives have also been involved in the development of substitute decision maker documents [9].

The importance of general practitioners in guiding patients' ACP is well documented and there are many studies examining how the uptake of ACP in general practice can be promoted [8, 10, 11]. As location of death is unpredictable, general practitioners remain central to ensuring advance care plans and end-of-life care are aligned with patient preferences where medically indicated and appropriate [12]. For people who died in high-income countries between 2010 and 15 [13], 47$60 \%$ died within the acute hospital setting [14-16]. In 2017, there was a discrepancy between the proportion of Australians who preferred die at home (70\%), and the number who actually did so $(50 \%)[17,18]$. Identifying temporal trends in these data is complicated by both a paucity of population-level data around patient preferences, and the concept that such preferences can change over time [19]. As such, it is important that patients' preferences are documented and communicated across healthcare settings.

Internationally, various legal rulings, legislations and guidelines outline how ACP is incorporated into medical practice [9, 20-25]. The state law in Victoria, Australia outlines that health practitioners must make a reasonable effort to determine the existence of an advance care plan [8]. While the creation of advance care plans is well documented, there is a dearth of literature analysing the communication of documents between parts of the healthcare system [26]. A formal pathway is not often followed, leading to uncertainty as to whether advance care plans that are made in general practice are accessible to hospital staff [27]. In Australia, current methods of ACP document communication from general practice to hospitals vary and include: facsimile, email, post or the patient bringing in their own documents from their place of residence [27].

The importance of ACP document communication has been supported by a High Court ruling in the United Kingdom, determining that all general practitioners must communicate any ACP documents to another treating healthcare service [28]. National registries and health records, such as the National Health Service Digital in the United Kingdom or My Health Record in Australia, may assist in bridging this gap in communication $[29,30]$ but as at March 2020, the number of ACP documents uploaded to My Health Record was $0.11 \%$ (26,920/22, $740,000)$ [31]. Within countries, there are inconsistencies in where and how ACP documents are stored within electronic health records [32-34]. Electronic record system alerts can be used to inform hospital staff that a patient file includes an ACP document [34, 35]. Defining this 'missing link' in the ACP process may assist in more people's preferences being known and respected during end-of-life care.

The aim of this study was to 1) identify the proportion of patients who died in a regional hospital without an ACP document system alert, and 2) determine whether these patients had an uncommunicated ACP document(s) remaining in their corresponding general practice record. The findings of this study will support policymakers seeking to identify strategies to improve the communication of ACP documents across health services and support the representation of patients' preferences during their end-of-life care.

\section{Methods \\ Study design and participants}

A retrospective cohort study of decedents' hospital and linked general practice records was conducted. This study was based in one large regional public hospital in Victoria, Australia and 35 general practices in the immediate surrounding local government area (LGA). The hospital services a population of over 300,000 people across $58,986 \mathrm{~km}^{2}$ [36].

The study sample was patients aged 75 years and over who died in the hospital between 1 January 2016 and 31 December 2017. For the assessment of linked general practice records, only the general practices situated in the same LGA as the hospital were included. The Australian Government Productivity Commission mandates that ACP form part of the general practice 
Medicare Health Assessment for Older Persons (75 and over), thus forming the rationale for the inclusion of the cohort age group and general practices [37]. This Health Assessment is only applicable to individuals aged over 75 years who lived at home and is a general review of current medical conditions and social circumstances [38]. ACP documents were limited to those legislated in the state of Victoria: advance care plan, Enduring Power of Attorney (Medical Treatment) or Enduring Power of Guardianship [8].

The presence of ACP documents in hospital medical records was assessed via the ACP system alert on the record. The general practice of decedents, who had lived in the immediate surrounding LGA, was noted. Thirty-five local general practice clinics were identified and invited to participate in the study via email and/or phone call to their respective Practice Managers. This invitation was followed by a handdelivered explanatory statement and consent form. In addition, the lead researcher met with a senior general practitioner from each clinic to explain the study. General practice clinics that had closed or changed owners were excluded as these decedents' records were no longer accessible. Manual record linkage occurred via the decedent's name and date of birth, with ACP document data then extracted.

\section{Data collection tool and extraction}

In the absence of a validated tool, a data extraction tool was developed and used to collect information from the general practice records. Key variables of interest were identified from Australian ACP policy documents $[8,18]$ and peer-reviewed literature [39-41]. These were the type of ACP document; patient gender, age, residential aged care facility (RACF) resident status; length of enrolment at the general practice; and whether they had received a Medicare Health Assessment for Older Persons (75 and over). A RACF in Australia is a purpose-built facility providing accommodation and nursing support [42]. The tool was piloted on $5 \%$ of records, resulting in minor modifications to reflect the provisional documents that were found. Data were extracted over a two-week period.

\section{Data analysis}

Following cleaning, the data were tested for normality using the Shapiro-Wilk test [43]. All continuous variables had a non-normal distribution, therefore medians with inter-quartile ranges were presented. Frequencies and corresponding percentages are reported for categorical data. Data were analysed using Statistical Package for Social Sciences for analysis [44].

\section{Results}

Of the 406 hospital decedents, 309 (76.1\%) died in hospital without an ACP document system alert on their hospital record (see Fig. 1).

Of the 35 general practices invited to participate, 17 (48.6\%) consented and 15 (42.9\%) declined. Two general practice clinics no longer existed, and another had changed ownership which resulted in the current practice not having access to previous patient records. Decedent numbers ranged from 3 to 21 per practice. This led to 144 (46.6\%) decedent hospital and general practice records being linked.

The characteristics of general practice decedents are outlined in Table 1 . Most decedents were aged 80 years or older. The median time the decedent had attended their nominated general practice clinic was 7.3 years $(\mathrm{IQR}=2.0-16.3)$. One in five of decedents lived in a RACF prior to death in hospital. The remainder were home residents and would have been eligible for a Medicare Health Assessment for Older Persons (75 and over) prior to their death. Of those who were eligible, half had participated in one of these health assessments.

Of the 144 general practice records, 21 (14.6\%) contained at least one ACP document that had not been communicated to the study hospital. Of these records, 14. (66.7\%) had only one document, either an Enduring Power of Attorney (Medical Treatment) $(n=11)$ or an Enduring Power of Guardianship $(n=3)$. Four $(19.0 \%)$ records included two ACP documents; two (9.5\%) included three documents. Of the four decedents with a written advance care plan, each had an Enduring Power of Attorney (Medical Treatment). Two of these also had an Enduring Power of Guardianship. Most ACP documents were made with the assistance of a lawyer or at their respective general practice. The median time from an ACP document being made to death was 2.5 years $(\mathrm{IQR}=0.5-4.9)$.

\section{Discussion}

To our knowledge, this is the first Australian study to examine the communication of ACP documents from general practice to a hospital. We found most decedents (76.1\%) did not have ACP document system alert in their hospital record. Of the 144 corresponding general practice records examined, $14.6 \%$ of these records contained an ACP document that was not communicated to the hospital nor alerted in their hospital record. It is likely that these documents found only in general practice records were not referenced during the inpatient end-of-life care period.

Previous research has highlighted a discordance between the creation, communication and availability of ACP documents [45]. A 2015 systematic review reported $21-53 \%$ of patients had completed an 


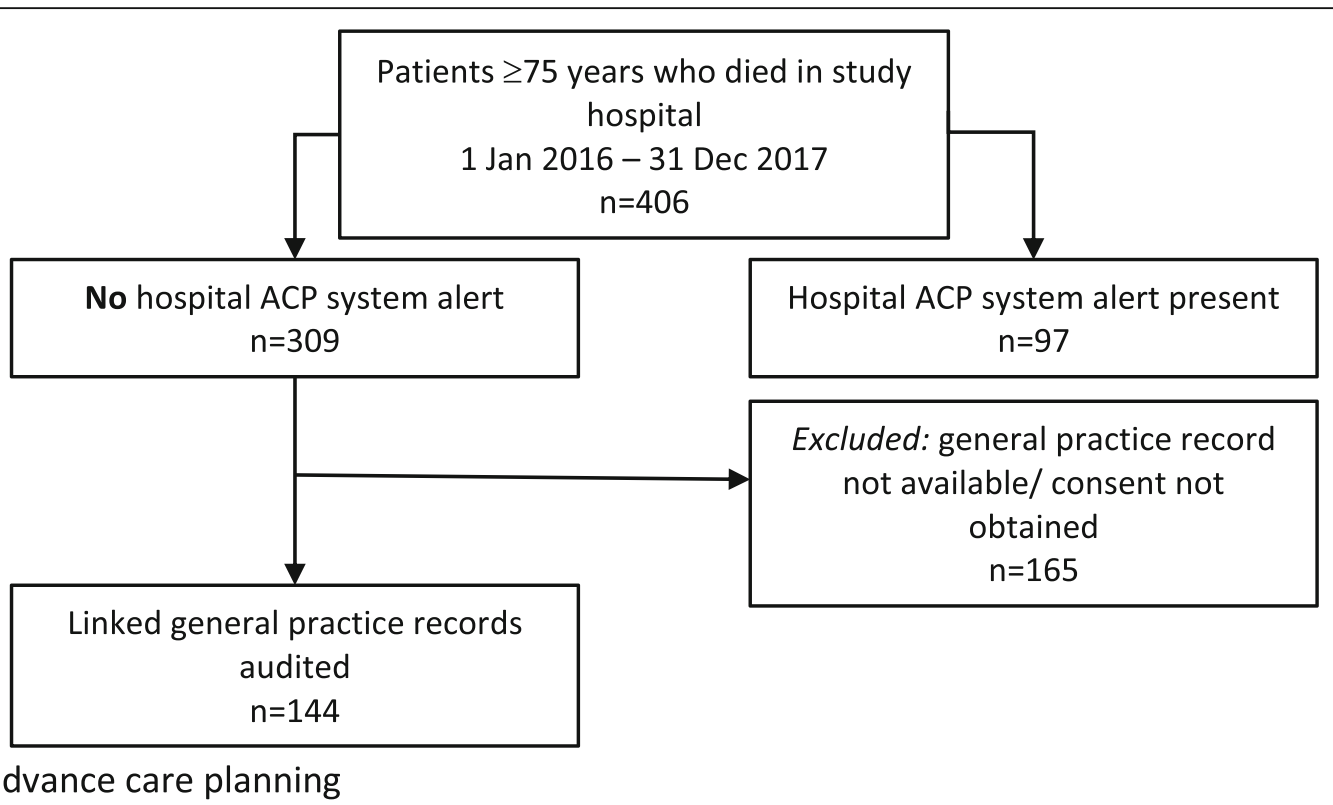

Fig. 1 Decedent record analysis. $A C P$, advance care planning

advance care plan but only between 1 and 44\% of these were available in emergency department records [26]. Our study only included decedent records; arguably those who we would expect to have the highest rates of ACP completion and availability during endof-life care. In Australia, there are numerous estimates $(14-29 \%)[39,46]$ of the completion of ACP documents in a range of population groups and the prevalence of ACP in hospital patients is 16\% [47].

Both patients and practitioners commit considerable time to ACP conversations and creating documents [48].
It is important that these documents are accessible to hospital staff to inform decisions which can enhance the quality of their patient's end-of-life care. It would be unjust to both the patient and their family if the preferences discussed during an ACP conversation, and any associated documents, are not shared across healthcare settings [49].

Without a sustainable approach to the communication of advance care plans from general practice to hospital, these documents may go unreferenced when clinically required if a patient loses decision making capacity.

Table 1 Characteristics of general practice decedents

\begin{tabular}{|c|c|c|}
\hline$n=144$ & & \\
\hline \multirow[t]{2}{*}{ Gender, n (\%) } & Female & $63(43.8)$ \\
\hline & Male & $81(56.2)$ \\
\hline Age (years), median (IQR) & & $84.9(81.0-89.4)$ \\
\hline \multirow[t]{3}{*}{ RACF resident } & Yes & $31(21.5)$ \\
\hline & No & $103(71.5)$ \\
\hline & Unknown & $10(7.0)$ \\
\hline Length of general practice enrolment (years), median (IQR) & & $7.3(2.0-16.3)$ \\
\hline \multirow[t]{3}{*}{ Medicare Health Assessment for Older Persons (75 and over) ${ }^{a}$} & Yes & $51(49.5)$ \\
\hline & No & $49(47.6)$ \\
\hline & Unknown & $3(2.9)$ \\
\hline Time between final Health Assessment and death (years) ${ }^{a}$, median (IQR) & & $1.0(0.5-1.9)$ \\
\hline Time between ACP document creation and death (years) ${ }^{\mathrm{b}}$, median (IQR) & & $2.5(0.5-4.9)$ \\
\hline
\end{tabular}

${ }^{a}$ Only applies to decedents who lived at home prior to hospital admission

bonly applies to decedents with an ACP document in their general practice record

Some percentages may not add up to $100 \%$ due to rounding

RACF Residential aged care facility, IQR Interquartile range; Health Assessment, Medicare Health Assessment for Older Persons (75 and over); ACP Advance care planning 
Although electronic, shared patient records can play a part in facilitating document communication to a hospital service, utilisation and access to these records in general practice and hospitals is not consistent [50]. National electronic health record systems face resistance regarding their overall functionality and the potential for medical information to be accessed by non-authorised third parties $[51,52]$. In Australia, an amendment to the My Health Records Act 2012 allows ACP documents to be uploaded by doctors on behalf of patients [53]. This may alleviate a barrier to uploading documents for older people as this age bracket is known to have poorer computer literacy than their younger counterparts [54]. As noted earlier, in Australia only $0.11 \%$ of My Health Record accounts contain an ACP document and not all hospitals can access these records in the acute setting [31]. Though accessibility will improve in time, the issues of communication and the implications of this persist.

In Australia, general practice and hospital records are not electronically linked [55]. The current methods of communicating ACP documents from general practice to hospitals (for example, facsimile, email, postal services and, in some rural areas, manual collection) are not sustainable [27]. Concerns regarding the confidentiality of electronic health records continue and in Australia, facsimile technology is being phased out of healthcare settings [56]. In locations where both the general practice and hospital(s) staff can access electronic health records, such as My Health Record, this mode of communication should be encouraged. Where these are not accessible, other methods need to be utilised. In rural areas, the local hospital is often the only provider of acute healthcare so it may be efficient to extend the use of existing electronic referral software to transmit ACP documents [27]. In metropolitan areas, patients may attend any number of hospitals so My Health Record could improve document availability for patients and doctors.

This study highlights the challenges faced by policymakers charged with integrating paper-based legal documents into an electronic health record system. Internationally, health services are shifting away from paperbased communication [57] and there is evidence that electronic health record systems improve the quality of patient care $[58,59]$. However, much of the research on the impact of such records on the cost and efficiency of healthcare has been based within siloed record systems that are limited by a defined set of providers or settings [59]. The greater challenge is how health information is communicated across electronic systems. ACP documents are not only created and stored in different electronic records, but also in legal settings or held by consumers themselves. Such challenges are not exclusive to the Australian setting [57] so this study also provides a foundation for future work in identifying methods and barriers to the communication of ACP documents both within and between healthcare providers.

This study had limitations. It was based in a single regional Australian public hospital and surrounding general practices, so the results may not be generalisable to other healthcare systems or metropolitan settings where patients may attend one of many hospitals. It was beyond the scope of the study to manually check all 409 decedents' hospital records for documents so there may have been some ACP documents in the hospital records that were not included on the hospital alert system. Due to the low prevalence of ACP documents, we were unable to determine whether an association between a Medicare Health Assessment for Older Persons (75 and over) and ACP documents exists. We only included ACP documents found in general practice records and did not examine RACF records. Although some RACFs have a protocol that a patient's record be copied when they are transferred to hospital, the presumption that RACFs send ACP documents with the patient may not be actuated [60]. Further research is needed to identify the prevalence of ACP documents remaining in RACF records.

\section{Conclusions}

General practitioners commit time and resources to assist their patients to document their end-of-life care preferences. We found most (76.1\%) hospital decedent records did not have an ACP document system alert. Of these, $14.6 \%$ of examined general practice records contained an ACP document that was unavailable for use during end-of-life care.

Electronic health record systems may be a long-term solution to the inconsistent communication of ACP documents from general practice to a hospital service. In the short-term, alternative methods of communication are needed to ensure health professionals are aware of documents, and where medically indicated, can respect patients' preferences during end-of-life care.

\section{Abbreviations}

ACP: Advance care planning; LGA: Local government area; RACF: Residential aged care facility

\section{Acknowledgements}

Not Applicable.

\section{Authors' contributions}

All authors ( $\mathrm{LP}, \mathrm{PH}, \mathrm{MJA}, \mathrm{DOC}, \mathrm{BW})$ were involved in the project conception. LP created the data collection tool, recruited general practices for participation and collected all data from the records. LP, BW and PH performed data analysis. LP drafted the initial manuscript. The final draft was reviewed by all authors (LP, PH, MJA, DOC, BW). All authors have read and approved the revised version of the manuscript.

\section{Funding}

This work has been supported by Better Safer Care Victoria. The funder has no role in the study design; data collection or analysis; article writing nor decision to submit this article for publication. 


\section{Availability of data and materials}

An anonymised form of the dataset used in this study is available from the corresponding author upon request.

\section{Ethics approval and consent to participate}

Ethical approval was granted by Monash University (reference: 12314) and the study hospital (reference: LNR/17/BHCG/63) Human Research Ethics Committees. Consent was granted by a representative of each of the participating general practices. A waiver of consent was granted by the ethics committee so that decedents' medical records could be examined.

\section{Consent for publication}

Publication consent was granted by the study hospital.

\section{Competing interests}

No author has declared any competing interests.

\section{Author details}

'School of Rural Health, Monash University, 26 Mercy Street, Bendigo, Victoria 3550, Australia. ${ }^{2}$ La Trobe Rural Health School, Edwards Road, Bendigo, Victoria 3550, Australia. ${ }^{3}$ Bendigo Health, 100 Barnard Street, Bendigo, Victoria 3550, Australia.

Received: 12 February 2020 Accepted: 2 July 2020 Published online: 14 July 2020

\section{References}

1. Advance Care Planning Australia. National advance care planning week 2020. Available from: https://www.advancecareplanning.org.au/acpweek\#/. Cited 2020 Feb 06

2. Waller A, Sanson-Fisher R, Ries N, Bryant J. Increasing advance personal planning: the need for action at the community level. BMC Public Health. 2018;18(1):606.

3. Mistry B, Bainbridge D, Bryant D, Tan Toyofuku S, Seow H. What matters most for end-of-life care? Perspectives from community-based palliative care providers and administrators. BMJ Open. 2015;5(6):e007492.

4. Detering KM, Silveira MJ. Advance care planning and advance directives: UpToDate; 2018. Available from: https://www.uptodate.com/contents/ advance-care-planning-and-advance-directives\#H23369095. Updated 2018 May 04; cited 2020 Feb 06

5. Advance Care Planning Australia. What is advance care planning? Melbourne: Austin Health; 2020. Available from: https://www. advancecareplanning.org.au/. Updated 2018; cited 2020 Feb 06.

6. McDermott E, Selman LE. Cultural factors influencing advance care planning in progressive, incurable disease: a systematic review with narrative synthesis. J Pain Symptom Manag. 2018;56(4):613-36.

7. Trankle SA, Shanmugam S, Lewis E, Nicholson M, Hillman K, Cardona M. Are we making Progress on communication with people who are near the end of life in the Australian health system? A thematic analysis. Health Commun. 2020;35(2):158-67.

8. Victorian Government. A guide to the medical treatment planning and decisions act 2016: for health practitioners. In: Department of Health and Human Services, editor. Victorian Government: Melbourne; 2017.

9. National Health Minister's Advisory Council. A national framework for advance care directives. In: Australian Government Department of Health and Ageing, editor. Canberra: Australian Government; 2011.

10. Mann J, Gill SD, Mitchell L, Rogers MJ, Martin P, Quirk F, et al. Locating advance care planning facilitators in general practice increases consumer participation. Aust Fam Physician. 2017;46(9):691-5.

11. De Vleminck A, Houttekier D, Pardon K, Deschepper R, Van Audenhove C, Vander Stichele $\mathrm{R}$, et al. Barriers and facilitators for general practitioners to engage in advance care planning: a systematic review. Scand J Prim Health Care. 2013;31(4):215-26.

12. Billingham MJ, Billingham S-J. Congruence between preferred and actual place of death according to the presence of malignant or non-malignant disease: a systematic review and meta-analysis. BMJ Support Palliat Care. 2013;3(2):144-54.

13. Organisation for Economic Co-operation and Development. Member countries 2019. Available from: https://www.oecd.org/about/members-andpartners/. Cited 2020 Feb 06.
14. Hall MJ, Levant S, DeFrances CJ. Trends in inpatient hospital deaths: National Hospital Discharge Survey, 2000-2010. NCHS Data Brief. 2013;118:1-8.

15. Australian Institute of Health and Welfare. Deaths in Australian hospitals 2014-15 Canberra: Australian Government; 2017. Available from: https:// www.aihw.gov.au/reports/hospitals/deaths-in-australian-hospitals-2014-15/ contents/summary/how-many-deaths-occur-in-hospital. Updated 2017 Mar 10; cited 2020 Feb 06.

16. gov.uk. Older people who died in hospital: England 2017. Available from: https://www.gov.uk/government/publications/older-people-who-died-inhospital-england-2017/older-people-who-died-in-hospital-england-2017. Cited 2020 Feb 06.

17. Australian Institute of Health and Welfare. Deaths in Australia: Australian Government; 2019. Available from: https://www.aihw.gov.au/reports/lifeexpectancy-death/deaths-in-australia/contents/leading-causes-of-death. Updated 2019 Jul 17; cited 2020 Feb 06.

18. Productivity Commission. Introducing Competition and Informed User Choice into Human Services: Reforms to Human Services - Inquiry report. Canberra: Australian Government; 2018. p. 109-69.

19. Mangin D, Stephen G, Bismah V, Risdon C. Making patient values visible in healthcare: a systematic review of tools to assess patient treatment priorities and preferences in the context of multimorbidity. BMJ Open. 2016;6(6): e010903.

20. Victorian Government. Melbourne: Medical Treatment Planning and Decisions Act. 2016.

21. Canadian Hospice Palliative Care Association. Advance Care Planning in Canada: National Framework. Ottawa: Health Canada; 2012.

22. Parliament of the United Kingdom. London: The Mental Capacity Act. 2005.

23. Wiesing $U$, Jox RJ, Heßler H-J, Borasio GD. A new law on advance directives in Germany. J Med Ethics. 2010;36(12):779-83.

24. United States Congress. Washington, D.C.: Patient Self-Determination Act. 1990

25. Mani RK, Simha SN, Gursahani R. The advance directives and foregoing of life support: where do we stand now? Indian J Crit Care Med. 2018;22(3):135-7.

26. Oulton J, Rhodes S, Howe C, Fain M, Mohler M. Advance directives for older adults in the emergency department: a systematic review. J Palliat Med. 2015;18(6):500-5.

27. Harvey P, Panozzo L, Adams MJ, O'Connor D, Ward B. Rural health services' relationships with patients: an enabler and a barrier to advance care planning. Aust J Rural Health. 2019;27(6):563-7.

28. Dyer C. GPs must pass on patients' advance treatment decisions to hospitals, says judge. BMJ. 2019;364:1504.

29. Australian Digital Health Agency. My wishes, my plan - advance care planning. Australian Government: Canberra; 2018.

30. NHS Digital. About NHS Digital 2019. Available from: https://digital.nhs.uk/ about-nhs-digital. Cited 2020 Feb 06.

31. Australian Bureau of Statistics. My Health Record statistics Canberra: Australian Government; 2020. Available from: https://www.myhealthrecord. gov.au/statistics. Cited 2020 May 05.

32. Scott IA, Mitchell GK, Reymond EJ, Daly MP. Difficult but necessary conversations--the case for advance care planning. Med J Aust. 2013; 199(10):662-6.

33. Panozzo L, Ward B, Harvey P, Fletcher J. Content and implementation of advance care plans: a retrospective cohort study. Aust J Gen Pract. 2019; 48(5):241-336.

34. Auret K, Sinclair C, Wilkinson A, Thomas J, Price D. Project to improve storage, access and incorporation of advance care plans in a regional Australian hospital. Aust J Rural Health. 2019;27(1):104-10.

35. Huber MT, Highland JD, Krishnamoorthi VR, Tang JW-Y. Utilizing the electronic health record to improve advance care planning: a systematic review. Am J Hosp Palliat Care. 2017;35(3):532-41.

36. Victorian Government. 2012 Regional health status profiles Loddon Mallee region. Health Do, editor. Melbourne: Victorian Government; 2012. p. 2.

37. Australia Government. Introducing competition and informed user choice into human services: reforms to human services. Canberra: Productivity Commission; 2017. p. 11-2.

38. Department of Health. Health assessment for people aged 75 years and older: Australian Government; 2014. Available from: https://www1.health. gov.au/internet/main/publishing.nsf/Content/mbsprimarycare_mbsitem_75 andolder. Updated 2014 Apr 10; cited 2020 Feb 06.

39. Auret K, Sinclair C, Averill B, Evans S. Advance care planning and end-of-life care in a network of rural Western Australian hospitals. Aust J Rural Health. 2015;23(4):195-200. 
40. Ruseckaite R, Detering KM, Evans SM, Perera V, Walker L, Sinclair C, et al. Protocol for a national prevalence study of advance care planning documentation and self-reported uptake in Australia. BMJ Open. 2017;7(11): e018024.

41. Leong LP, Crawford GB. Residential aged care residents and components of end of life care in an Australian hospital. BMC Palliat Care. 2018;17(1):84-93.

42. Australian Institute of Health and Welfare. Residential aged care facility Canberra Australian Government 2020. Available from: https://meteor.aihw. gov.au/content/index.phtml/itemld/384424. Cited 2020 May 09.

43. Shapiro SS, Wilk MB. An analysis of variance test for normality (complete samples). Biometrika. 1965;52(3-4):591-611.

44. IBM Analytics. IBM SPSS software: IBM; 2018. Available from: https://www. ibm.com/analytics/au/en/technology/spss/. Cited 2020 Feb 06.

45. Lakin JR, Isaacs E, Sullivan E, Harris HA, McMahan RD, Sudore RL. Emergency Physicians' experience with advance care planning documentation in the electronic medical record: useful, needed, and elusive. J Palliat Med. 2016; 19(6):632-8.

46. White B, Tilse C, Wilson J, Rosenman L, Strub T, Feeney R, et al. Prevalence and predictors of advance directives in Australia. Intern Med J. 2014;44(10): 975-80.

47. Buck K, Detering K, Sellars M, Ruseckaite R, Kelly H, Nolte L. Prevalence of advance care planning documentation in Australian health and residential aged care services, short report. Advance care planning Australia. Austin Health: Melbourne; 2017.

48. Jimenez G, Tan WS, Virk AK, Low CK, Car J, Ho AHY. Overview of systematic reviews of advance care planning: summary of evidence and global lessons. J Pain Symptom Manage. 2018;56(3):436-59.e25.

49. The Royal Australian College of General Practitioners. Your Medicare rebates have been frozen - fast facts. 2018.

50. Khairat S, Coleman GC, Russomagno S, Gotz D. Assessing the status quo of ehr accessibility, usability, and knowledge dissemination. EGEMS (Wash DC). 2018;6(1):9.

51. Lehnbom EC, Douglas HE, Makeham MAB. Positive beliefs and privacy concerns shape the future for the personally controlled electronic health record. Intern Med J. 2016:46(1):108-11.

52. Entzeridou E, Markopoulou E, Mollaki V. Public and physician's expectations and ethical concerns about electronic health record: benefits outweigh risks except for information security. Int J Med Inform. 2018;110:98-107.

53. My Health Records Amendment (Advance Care Planning Information and Professional Representatives) Rule 2016, (2018).

54. Thomas J, Barraket J, Wilson C, Cook K, Louie Y, Holcombe-James I, et al. Measuring Australia's Digital divide - the Australian Digital inclusion index 2018. Melbourne: RMIT University; 2018. p. 5.

55. Canaway R, Boyle DIR, Manski-Nankervis J-AE, Bell J, Hocking JS, Clarke K, et al. Gathering data for decisions: best practice use of primary care electronic records for research. Med J Aust. 2019;210(S6):S12-S6.

56. Australian Government. Fax machines on the way out for Australian healthcare Canberra: Australian Digital health agency; 2017. Available from: https:/www. digitalhealth.gov.au/news-and-events/news/fax-machines-on-the-way-out-foraustralian-healthcare. Updated 2017 Jul 14; cited 2020 Feb 06

57. Evans RS. Electronic Health Records: Then, Now, and in the Future. Yearb Med Inform. 2016;Suppl 1(Suppl 1):S48-61.

58. Wani D, Malhotra M. Does the meaningful use of electronic health records improve patient outcomes? J Oper Manag. 2018;60:1-18.

59. Atasoy H, Greenwood BN, McCullough JS. The digitization of patient care: a review of the effects of electronic health records on health care quality and utilization. Annu Rev Public Health. 2019:40:487-500.

60. Australian Commission on Quality and Safety in Healthcare. Procedure for use of aged care home transfer-to-hospital envelope. Sydney: Australian Commission on Quality and Safety in Healthcare; 2009.

\section{Publisher's Note}

Springer Nature remains neutral with regard to jurisdictional claims in published maps and institutional affiliations.

Ready to submit your research? Choose BMC and benefit from:

- fast, convenient online submission

- thorough peer review by experienced researchers in your field

- rapid publication on acceptance

- support for research data, including large and complex data types

- gold Open Access which fosters wider collaboration and increased citations

- maximum visibility for your research: over $100 \mathrm{M}$ website views per year

At $\mathrm{BMC}$, research is always in progress.

Learn more biomedcentral.com/submissions 